\title{
Effect of the Timing of Fungicide Application on Fusarium Head Blight and Mycotoxin Contamination in Wheat
}

Megumi Yoshida, Takashi Nakajima, Kenta Tomimura, Fumihiko Suzuki, Michiyoshi Arai, and Atsushi Miyasaka, NARO

Kyushu Okinawa Agricultural Research Center (NARO/KARC), 2421 Suya, Koshi, Kumamoto 861-1192, Japan

\begin{abstract}
Yoshida, M., Nakajima, T., Tomimura, K., Suzuki, F., Arai, M., and Miyasaka, A. 2012. Effect of the timing of fungicide application on Fusarium head blight and mycotoxin contamination in wheat. Plant Dis. 96:845-851.

Fungicide application to control Fusarium head blight (FHB) and accompanying mycotoxin contamination in wheat is generally performed at anthesis because wheat is most susceptible to FHB around this stage. In this study, we evaluated the effect of the timing of fungicide application on FHB and mycotoxin (deoxynivalenol and nivalenol) accumulation in wheat based on our previous finding that the late period of grain development (beyond 20 days after anthesis [DAA]) is important to determine the final toxin contamination level in wheat. Thiophanate-methyl fungicide was tested under artificial inoculation conditions in which moisture and inoculum spores were

provided throughout the testing period. Eight treatments differing in application timing (anthesis, 10, 20, and 30 DAA) and in the number of applications (0 to 2) were tested for 2 years. The results indicated that fungicide application timing differentially affects FHB (disease) and mycotoxin concentration. Fungicide application at 20 DAA reduced mycotoxin concentration in matured grain without reducing FHB severity, whereas application at anthesis was crucial for reducing FHB. These results and our previous findings suggest that around 20 DAA (late milk stage) is a potentially critical timing for mycotoxin control in wheat.
\end{abstract}

Fusarium head blight (FHB), a destructive disease of wheat (Triticum aestivum L.), barley, and other small-grain cereals, is caused by several Fusarium spp. $(17,18,26,29)$. These pathogens infect spikes and reduce grain yield and quality. Moreover, Fusarium spp. that cause FHB produce trichothecene mycotoxins such as deoxynivalenol (DON) and nivalenol (NIV) and the estrogenic mycotoxin zearalenone. Such mycotoxins are toxic to humans and other animals. Contamination of wheat and barley by these mycotoxins has been reported worldwide $(31,41,42)$.

The Fusarium graminearum species complex $(23-25,37,46)$, once considered a single species ( $F$. graminearum Schwabe, teleomorph: Gibberella zeae (Schwein.) Petch), is the main causal organism of FHB in Japan (14). The $F$. graminearum species complex consists of at least 13 biogeographically structured, phylogenetically distinct species $(23-25,37,46)$. Most Japanese strains of the $F$. graminearum species complex are $F$. asiaticum or $F$. graminearum sensu stricto $(23,38)$.

Trichothecene metabolite profiles (chemotypes) for the $F$. graminearum species complex are strain specific: some strains produce mainly DON, whereas others produce mainly NIV $(11,15,35,45)$. Both chemotypes of the $F$. graminearum species complex are present in Japan $(10,22,38,50,51)$, and natural contamination of wheat with both DON and NIV occurs $(41,42,50,51)$. Additionally, co-contamination with DON and NIV is common $(41,42,50,51)$. More importantly, NIV is reported to be more toxic to animals than is DON $(33,40,44)$. Therefore, control of FHB and of DON and NIV contamination is essential for wheat production in Japan.

There is currently no robust single control measure by which to manage either FHB or mycotoxin contamination in wheat. Fungicide application is one measure available to reduce the risk; however, results have not been highly effective or consistent $(12,13,19,27,28)$. To achieve increased chemical control of FHB,

Corresponding author: T. Nakajima, E-mail: ntakashi@affrc.go.jp

Accepted for publication 23 December 2011.

http://dx.doi.org/10.1094/PDIS-10-11-0819

(C) 2012 The American Phytopathological Society the timing of fungicide application is an important factor, as are fungicide selection, application rate, and good coverage of the spike (19).

For wheat, anthesis is regarded as the optimal growth stage for fungicide application to control FHB $(13,19)$. This is reasonable because wheat is most susceptible to FHB during anthesis $(3,26,32,39)$, which is when the anthers extrude from the florets. Initial Fusarium spp. infection commonly occurs on extruded anthers (32).

Our previous study (47) indicated that wheat is most susceptible to FHB during anthesis, and disease severity on the spikes sharply declined with delay in infection timing (from 0 to 20 days after anthesis [DAA]), which supported previously reported findings. In the same study, interestingly, we also found that (i) the amount of DON and NIV largely increased in grain after 20 DAA (late milk stage), even with infection at earlier stages, and (ii) infection at late stages, at least as late as 20 DAA, can cause non-ignorable levels of contamination with these toxins in grain, even without clear FHB symptoms. These findings indicate the importance of the late stage in grain development in DON and NIV contamination in wheat. Practically, this would mean that, if we can control toxin production during the late stage, the final toxin level would be effectively reduced.

Thus, we hypothesized that fungicide application during late developmental stages can effectively reduce the mycotoxin contamination level in matured wheat grain. To date, several studies have examined the effect of fungicide application in controlling FHB and mycotoxin accumulation in wheat. However, in most studies, fungicides are applied at or near the flowering stage of the host $(4,9,12,13,16,19,20)$. To our knowledge, there has been no published study investigating the effect of fungicide on FHB and mycotoxin when applied at late developmental stages.

The objective of this study was to evaluate the effect of various timings (i.e., from anthesis to as late as 30 DAA) of fungicide application on FHB and mycotoxin (DON and NIV) accumulation in wheat, particularly focusing on the effect of late timings of application.

\section{Materials and Methods}

Plant materials. The effects of the timing of fungicide application on wheat were evaluated during 2005 and 2006. The experi- 
ments were performed in the field at the NARO Kyushu Okinawa Agricultural Research Center (NARO/KARC), in Koshi $\left(32.9^{\circ} \mathrm{N}\right.$,

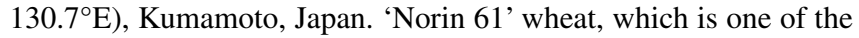
most widely grown Japanese cultivars used to make Japanese noodles, was used in both years. Norin 61 is moderately resistant to FHB. This cultivar was planted on 25 and 24 November in 2004 and 2005, respectively, in single rows that were $0.8 \mathrm{~m}$ apart and 50 $\mathrm{m}$ long. The plants were grown in accordance with standard agronomic practices until heading.

Inoculation and spore monitoring. Inoculation was performed using colonized maize kernel inoculum $(5,8)$, which generates ascospores over a long period during the testing season in the field. As inoculum, a mixture of four isolates of the $F$. graminearum species complex differing in trichothecene chemotype, DON types H-3 ( $F$. graminearum sensu stricto MAFF101551) and DON-5 (F. asiaticum MAFF240559 [22,38]), and NIV types NIV-1 (MAFF240547) and NIV-7 (MAFF240552) (both F. asiaticum $[22,38])$, were used.

The colonized maize kernels of each isolate were prepared as described in a previous study (48). One liter of maize kernels in 2liter Erlenmeyer flasks was autoclaved at $121^{\circ} \mathrm{C}$ for $1 \mathrm{~h}$. A macroconidial suspension of each isolate ( 1 to $4 \times 10^{5}$ conidia/ml $)$ was injected into flasks (110 $\mathrm{ml}$ of suspension per flask) and shaken; then, the flasks were maintained at $25^{\circ} \mathrm{C}$ for 2 weeks to permit thorough colonization of the kernels. During incubation, the flasks were periodically shaken. After 2 weeks of incubation, the colonized maize kernels were spread in stainless vats, and naturally dried for 3 days. The dried kernels were stored at $-20^{\circ} \mathrm{C}$ until use (approximately 2 months). On 24 March 2005 and 27 March 2006, the colonized maize kernels of the four isolates were mixed in equal volumes and distributed in the field by hand at rates of 48 and $43 \mathrm{~cm}^{3} / \mathrm{m}^{2}$, respectively. In total, approximately 24 and 21.5 liters of colonized maize kernels were distributed in the field (approximately $500 \mathrm{~m}^{2}$ ) in 2005 and 2006, respectively.

Mist irrigation to promote ascospore production and fungal infection was performed in the field using a sprinkler system with DN881A-type sprinkler heads equipped with 1.50-mm-diameter nozzles (Sun Hope, Inc., Meguro-ku, Tokyo). The sprinkler system was set up with the sprinkler heads spaced approximately $2 \mathrm{~m}$ apart and was activated on 4 April 2005 and 18 April 2006, corresponding to 17 and 2 days before heading (Zadoks growth stage [ZGS] 52 to 53; one-quarter of the inflorescence emerged in $>50 \%$ of spikes) (53), respectively. The start of irrigation was delayed in 2006 because there was frequent natural precipitation from the beginning of April in that year. Water was applied four times daily (at 0100, 0700, 1300, and $1900 \mathrm{~h}$ ) for $15 \mathrm{~min}$ at each time in 2005 and for $6 \mathrm{~min}$ at each time in 2006 at a rate of approximately 25 $\mathrm{mm} / \mathrm{h}$. On rainy days, irrigation was not performed. Misting was continued until 5 and 3 days before harvest in 2005 and 2006, respectively. Daily mean temperature and precipitation amount during the test period were recorded at the meteorological station at NARO/KARC, located approximately $750 \mathrm{~m}$ north of the test field.

The daily inoculum spore load ( $F$. graminearum species complex spores) during the test period was monitored at 1- to 6-day intervals using the selective medium (FG medium; 43). Before heading, a plate stand ( 80 by 20 by $20 \mathrm{~cm}$ high) with a roof ( 180 by 70 by $80 \mathrm{~cm}$ high) was set up in the center of the field. On each monitoring day, three plates of FG medium (in 9-cm-diameter plastic petri dishes) were placed on the stand in a row at a spacing of $10 \mathrm{~cm}$ between 1630 and $1730 \mathrm{~h}$ each day, and they were retrieved on the next day between 0830 and $0930 \mathrm{~h}$. The plates were then covered with lids, sealed with Parafilm, and incubated under fluorescent light at room temperature $\left(23 \pm 2^{\circ} \mathrm{C}\right)$. After approximately 1 week, colonies of $F$. graminearum species complex, identified as having white aerial hyphae on the surface and a bright red color from the underside of plates, were counted, and the average of three plates was calculated.

Experimental design and fungicide treatments. The fungicide treatments tested in this study are shown in Table 1. The Roman numerals I and II indicate the number of fungicide applications (i.e., 1 and 2, respectively) for each treatment. Treatments I- 1 to -4 indicate single applications at $0,10,20$, and 30 DAA, respectively. Treatments II- 1 to -3 are two applications at $0+10,0+20$, and $0+$ 30 DAA, respectively. The fungicide application at anthesis $(0$ DAA) was performed on 28 April 2005 and 1 May 2006. The application timings $(0,10,20$, and $30 \mathrm{DAA})$ corresponded to midanthesis (ZGS 64 to 65 ), early milk (ZGS 73), late milk (ZGS 77), and early to soft dough (ZGS 83 to 85) stages, respectively.

All eight treatments were assigned to 4-m single-row plots that were arranged at $0.5-\mathrm{m}$ intervals in a randomized complete block design in the field consisting of $1250-\mathrm{m}$-long rows spaced $0.8 \mathrm{~m}$ apart. Adjacent rows were left untreated as border rows. Each treatment was replicated three and four times in 2005 and 2006, respectively.

Table 1. Fungicide treatments tested in this study and Fusarium head blight (FHB) incidence (I), FHB severity (S), percentage of Fusarium-damaged kernels (FDK), and deoxynivalenol (DON) and nivalenol (NIV) concentration after each treatment in each study year ${ }^{\mathrm{X}}$

\begin{tabular}{|c|c|c|c|c|c|c|c|c|c|c|c|}
\hline \multirow[b]{2}{*}{ Year, treatment } & \multirow[b]{2}{*}{ Total $^{\mathbf{z}}$} & \multicolumn{4}{|c|}{ Application timing (DAA) $)^{\mathbf{y}}$} & \multirow[b]{2}{*}{ FHB I (\%) } & \multirow[b]{2}{*}{ FHB S (0-100) } & \multirow[b]{2}{*}{$\operatorname{FDK}(\%)$} & \multirow[b]{2}{*}{ DON $(\mu \mathrm{g} / \mathrm{g})$} & \multirow[b]{2}{*}{ NIV $(\mu \mathrm{g} / \mathrm{g})$} & \multirow[b]{2}{*}{ DON+NIV $(\mu \mathrm{g} / \mathrm{g})$} \\
\hline & & $\mathbf{0}$ & 10 & 20 & 30 & & & & & & \\
\hline \multicolumn{12}{|l|}{2005} \\
\hline $\mathrm{I}-1$ & 1 & 0 & $\ldots$ & $\ldots$ & $\ldots$ & 61 & 8 & 7.2 & 3.8 & 0.7 & 4.5 \\
\hline $\mathrm{I}-2$ & 1 & $\ldots$ & 0 & $\ldots$ & $\ldots$ & 95 & 33 & 12.7 & 6.7 & 1.5 & 8.2 \\
\hline I-3 & 1 & $\ldots$ & $\ldots$ & 0 & $\ldots$ & 100 & 32 & 8.1 & 4.0 & 0.8 & 4.8 \\
\hline $\mathrm{I}-4$ & 1 & $\ldots$ & $\ldots$ & $\ldots$ & 0 & 100 & 32 & 13.2 & 7.4 & 1.3 & 8.6 \\
\hline II-1 & 2 & 0 & 0 & $\ldots$ & $\ldots$ & 51 & 5 & 3.7 & 2.1 & 0.4 & 2.5 \\
\hline II-2 & 2 & 0 & $\ldots$ & 0 & $\ldots$ & 59 & 7 & 2.4 & 1.1 & 0.3 & 1.4 \\
\hline II-3 & 2 & 0 & $\ldots$ & $\ldots$ & 0 & 73 & 10 & 6.4 & 3.3 & 0.6 & 3.9 \\
\hline No fungicide & 0 & $\ldots$ & $\ldots$ & $\ldots$ & $\ldots$ & 100 & 44 & 14.2 & 7.4 & 1.6 & 8.9 \\
\hline \multicolumn{12}{|l|}{2006} \\
\hline $\mathrm{I}-1$ & 1 & 0 & $\ldots$ & $\ldots$ & $\ldots$ & 79 & 9 & 6.7 & 1.6 & 1.1 & 2.7 \\
\hline $\mathrm{I}-2$ & 1 & $\ldots$ & 0 & $\ldots$ & $\ldots$ & 90 & 12 & 6.1 & 1.2 & 0.8 & 2.0 \\
\hline $\mathrm{I}-3$ & 1 & $\ldots$ & $\ldots$ & 0 & $\ldots$ & 94 & 14 & 4.7 & 1.0 & 0.6 & 1.6 \\
\hline I-4 & 1 & $\ldots$ & $\ldots$ & $\ldots$ & 0 & 93 & 14 & 5.1 & 1.2 & 0.8 & 2.0 \\
\hline II-1 & 2 & 0 & 0 & $\ldots$ & $\ldots$ & 71 & 7 & 5.8 & 1.2 & 0.7 & 2.0 \\
\hline II-2 & 2 & 0 & $\ldots$ & 0 & $\ldots$ & 75 & 9 & 3.3 & 0.7 & 0.5 & 1.1 \\
\hline II-3 & 2 & 0 & $\ldots$ & $\ldots$ & 0 & 77 & 8 & 5.6 & 1.1 & 0.7 & 1.8 \\
\hline No fungicide & 0 & $\ldots$ & $\ldots$ & $\ldots$ & $\ldots$ & 91 & 14 & 5.1 & 1.5 & 0.9 & 2.4 \\
\hline
\end{tabular}

$x$ Values indicate the mean of three or four replications per treatment.

y The application timing (i.e., 0, 10, 20, and 30 days after anthesis [DAA]) corresponded to mid-anthesis (Zadoks growth stage [ZGS] 64 to 65), early milk (ZGS 73), late milk (ZGS 73), and early to soft dough (ZGS 83 to 85) stages, respectively. Circles under each application timing indicate that thiophanatemethyl fungicide was applied at those times during the treatment.

${ }^{\mathrm{z}}$ Total application times. 
A wettable powder of Topsin M (Nippon Soda Co., Ltd., Chiyodaku, Tokyo) containing 70\% thiophanate-methyl as the active ingredient (a.i.) was used as the fungicide treatment. Topsin $\mathrm{M}$ is one of the most widely used fungicides to control FHB in wheat and barley in Japan $(1,2)$. This product was diluted in water at $1 \mathrm{~g} \mathrm{liter}^{-1}$ and a spreader, New Gramin (Sankyo Agro Co., Ltd., Minato-ku, Tokyo), was added at $0.3 \mathrm{ml} \mathrm{liter}^{-1}$; the mixture was applied at a rate of $150 \mathrm{ml} / \mathrm{m}^{2}$ using manual pressure sprayers with 1.2-liter capacity (T-1; Sakata Seed Co., Yokohama, Japan). This was equivalent to $1,050 \mathrm{~g}$ a.i./ha. Fungicide application was performed between 1300 and $1500 \mathrm{~h}$ on each designated day. Sprinkler irrigation at $1300 \mathrm{~h}$ was not performed on the days of fungicide application.

Disease and post-harvest assessments. FHB was assessed at 20 DAA in both years (ZGS 77; late milk stage). Fifty spikes were arbitrarily selected from each plot and assessed for FHB severity on a scale of 0 to 100 (scores of $0,5,10,20,30,40,50,60,70,80$, 90 , and 100, according to visual rating of the percentage of discolored area of the spike), as in previous studies $(47,49)$, and the average was calculated for each plot. Using these data, FHB incidence (percentage; i.e., the percentage of visually diseased spikes) was also calculated for each plot.

At physiological maturity (ZGS 91; 39 and 37 DAA in 2005 and 2006, respectively), all spikes within $2 \mathrm{~m}$ of the middle of each single-row plot were harvested by hand. The spikes were dried at $70^{\circ} \mathrm{C}$ for $24 \mathrm{~h}$ and threshed with a thresher. The harvested grain samples were cleaned manually. The percentage of Fusarium spp.damaged kernels (FDK; visibly bleached and shriveled kernels) was measured for each grain sample. The DON and NIV contents

\section{5}

Timing of fungicide application (DAA)

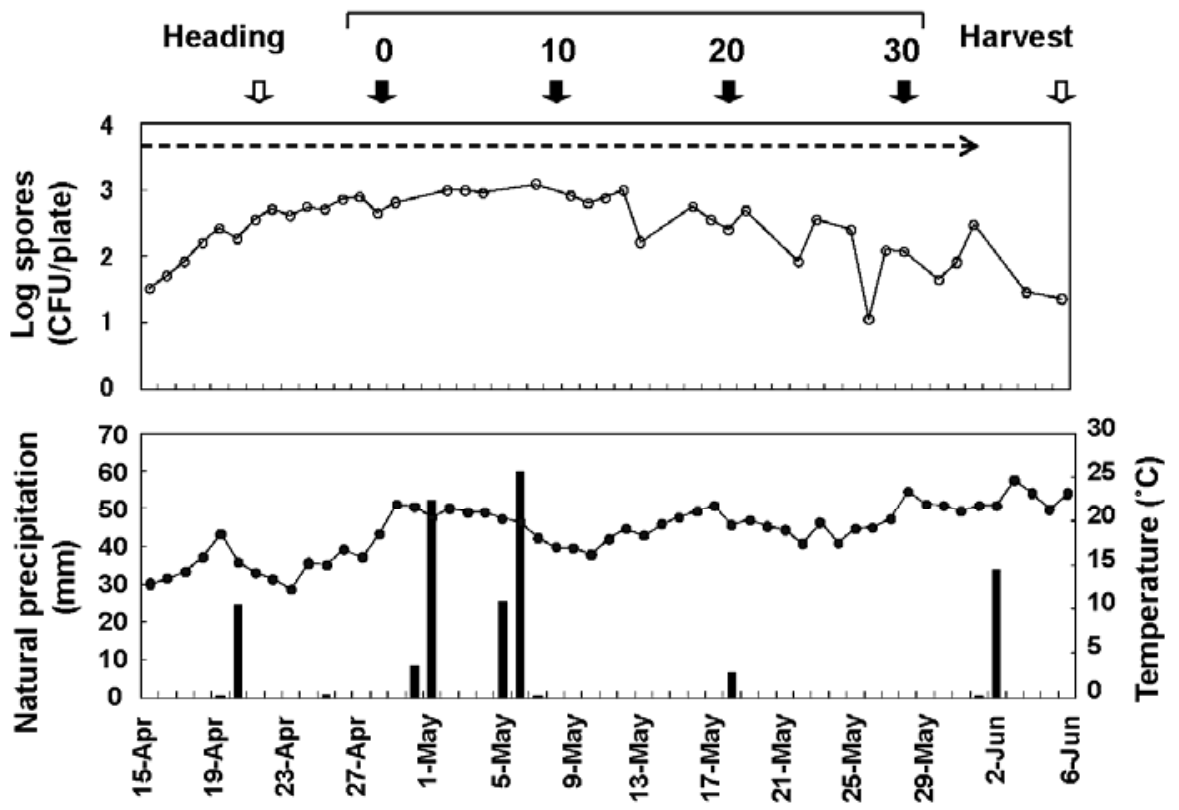

2006

Timing of fungicide application (DAA)

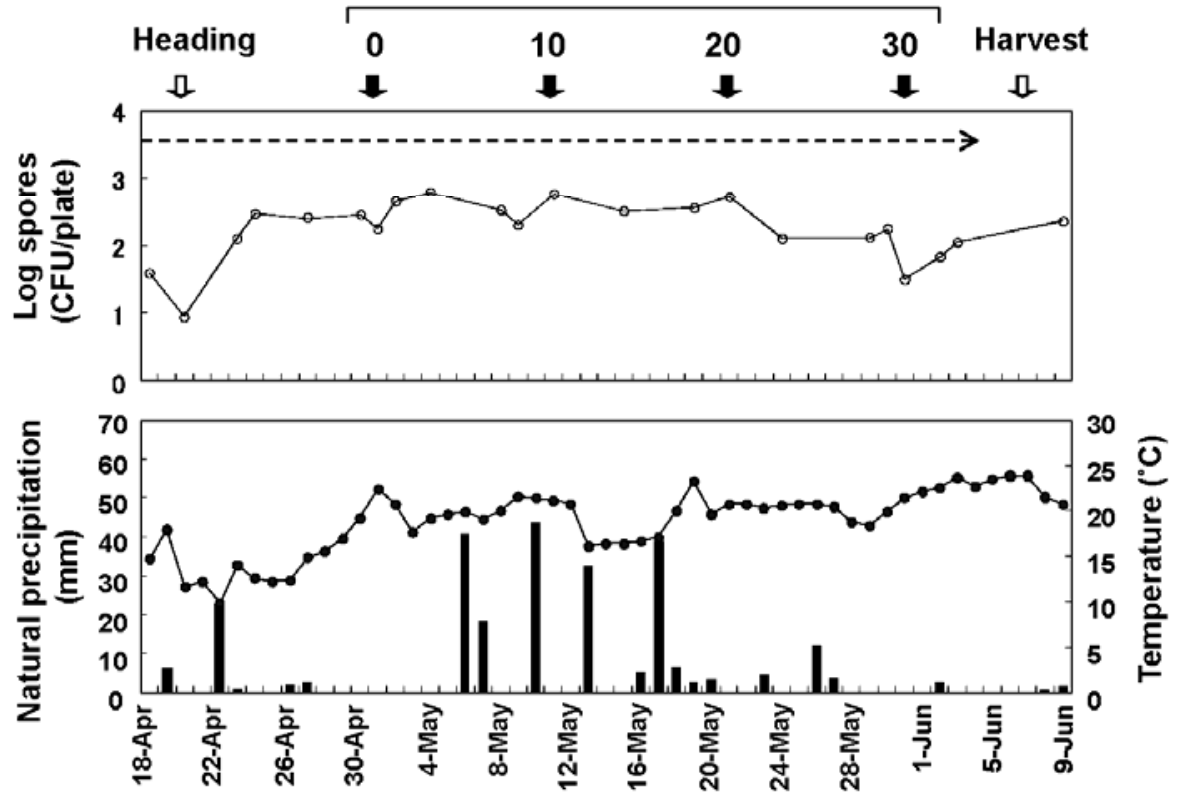

Fig. 1. Daily inoculum spore load of Fusarium graminearum species complex trapped on the selective medium, daily mean temperature, and daily precipitation during the test period in each study year. Broken arrows indicate periods of sprinkler irrigation, performed four times a day. Timings of fungicide application are indicated by bold solid arrows with the days after anthesis (DAA). Bold open arrows indicate the day of heading and harvest. 
were analyzed for $100 \mathrm{~g}$ of each grain sample using the previously described enzyme-linked immunosorbent assay system (52) of the KM Assay Center, Kyowa Medex Co., Ltd. (Nagaizumi-cho, Shizuoka, Japan).

Statistical analyses. The data of FHB incidence, FHB severity, FDK percentage, and total mycotoxin content (DON + NIV) were analyzed among some of the treatments with the analysis of variance (ANOVA) followed by Fisher's protected least significant difference (Fisher's PLSD) test at $P=0.05$ to evaluate the effect of (i) one-time fungicide application at different timings and (ii) different timings of additional fungicide application after a 0-DAA application in each year. The data of FHB incidence, FHB severity, and FDK percentage were arcsine square-root transformed for data analysis. All the statistical analyses were performed with JMP 9 statistical discovery software (SAS Institute, Cary, NC).

The control efficacy of each fungicide treatment for FHB severity and DON + NIV content was calculated for each year using the formula $[(K-P) / K] \times 100$, where $K$ is the mean of each assessed parameter in the no-fungicide control plots and $P$ is the mean of each parameter in the treated plots.

\section{Results}

Spore monitoring and meteorological data. The numbers of $F$. graminearum species complex spores trapped on the selective medium over the test period are shown in Figure 1, together with the meteorological data and the timing of heading (ZGS 52 to 53; onequarter of the inflorescence emerged in $>50 \%$ of spikes) of host plant, harvest, and fungicide application for each year.

In both years, $F$. graminearum species complex spores were observed throughout the test period. The number of $F$. graminearum species complex spores trapped on the first day of fungicide application (0 DAA; mid-anthesis, ZGS 64 to 65 ) was $4.4 \times 10^{2}$ and $1.8 \times 10^{2} \mathrm{CFU} /$ plate in 2005 and 2006, respectively, and the average of daily number of trapped spores from 0 DAA to 2 days before harvest was $4.7 \times 10^{2}$ and $2.8 \times 10^{2} \mathrm{CFU} /$ plate in 2005 and 2006 , respectively. The daily number of $F$. graminearum species complex spores was not correlated with natural precipitation, probably because of sprinkler irrigation during this period.

Effect of fungicide application treatments on disease and post-harvest parameters. All data (FHB incidence, FHB severity, FDK percentage, and mycotoxin content) for each treatment in each year are shown in Table 1. The disease level of the nofungicide control plots was severe in 2005 (FHB incidence $=100 \%$ and FHB severity $=44$ ), whereas it was moderate in 2006 (FHB incidence $=91 \%$, FHB severity $=14$ ). The FDK percentage and mycotoxin content in the grain of the no-fungicide control plots were also higher in $2005(\mathrm{FDK}=14.2 \%, \mathrm{DON}+\mathrm{NIV}=8.9 \mu \mathrm{g} / \mathrm{g})$ than in 2006 (FDK $=5.1 \%$, DON + NIV $=2.4 \mu \mathrm{g} / \mathrm{g})$.

To evaluate the effect of a single application of fungicide at different timings, the data of disease and post-harvest parameters were compared (ANOVA followed by Fisher's PLSD test) among treatments I-1 to -4 (i.e., application at $0,10,20$, and 30 DAA, respectively) and the no-fungicide control in each year (Table 2). The effect of treatments was significant at $P<0.05$ for disease level (FHB I and FHB S), and the disease levels with treatment I-1 (application at anthesis) were significantly lower than those with no-fungicide treatment in both years. Disease levels with other treatments (treatments I-2 to -4) were not significantly different from that in the no-fungicide control. For mycotoxin content (DON + NIV), the effect of treatments was significant at $P<0.05$ in 2006. In that year, the toxin level with treatment I-3 (application at 20 DAA) was significantly lower than that of the no-fungicide control. In 2005, although the effect of treatments was not significant at $P<0.05$, the $P$ value of the ANOVA was $<0.1$ and the mycotoxin content with treatment I-3 as well as treatment I-1 was at least numerically lower than that of the no-fungicide control. The effect of treatments for FDK was not significant in both years.

The level of control efficacy of each treatment for the mycotoxin content did not correspond with that for FHB severity in the comparisons (Table 2). For FHB severity, the control efficacy of treatment I-1 was highest among the treatments in both years. The control efficacy of treatment I-1 for FHB S was 82 in 2005 and 36 in 2006. By contrast, for mycotoxin content, the control efficacy of treatment I-3 was relatively high among the treatments in both years: 46 in 2005 and 34 in 2006. In 2005, the control efficacy of treatment I-1 for mycotoxin content was also high, as was that of treatment I-3.

To evaluate the effect of different timings of additional fungicide application after the 0-DAA application, the disease and postharvest data were also compared among treatments I-1 and II- 1 to -3 in each year (Table 3 ). In both years, the effects of the treatments for FHB I and FHB S were not significant. However, the effect of the treatments for mycotoxin content was significant $(P<0.05)$ in 2006. Among the treatments with additional fungicide application (treatments II-1 to -3), the toxin level with treatment II-2 (additional fungicide application was performed 20 DAA after the 0DAA application) was significantly lower than that with treatment I-1 (no additional fungicide application) in 2006. In 2005, although the effect of treatments was not significant at $P<0.05$, the $P$ value was $<0.1$ and the mycotoxin content with treatment II- 2 was lowest among the treatments numerically. Regarding the effect of the treatments for FDK, it was significant $(P<0.05)$ in 2005 and the

Table 2. Effect of various timings of fungicide application on Fusarium head blight (FHB) incidence (I), FHB severity (S), percentage of Fusarium-damaged kernels (FDK), and deoxynivalenol (DON) and nivalenol (NIV) concentration in wheat ('Norin 61') in each study year'

\begin{tabular}{|c|c|c|c|c|c|c|c|}
\hline \multirow[b]{2}{*}{ Year, treatment } & \multirow[b]{2}{*}{$\mathbf{D A} \mathbf{A}^{\mathbf{z}}$} & \multirow[b]{2}{*}{ FHB I (\%) } & \multirow[b]{2}{*}{ FHB S (0-100) } & \multirow[b]{2}{*}{$\operatorname{FDK}(\%)$} & \multirow[b]{2}{*}{ DON+NIV $(\mu \mathrm{g} / \mathrm{g})$} & \multicolumn{2}{|c|}{ Control efficacy for } \\
\hline & & & & & & FHB S & DON+NIV \\
\hline \multicolumn{8}{|l|}{2005} \\
\hline I-1 & 0 & $61 \mathrm{~b}$ & $8 \mathrm{~b}$ & 7.2 & 4.5 & 82 & 50 \\
\hline $\mathrm{I}-2$ & 10 & $95 \mathrm{a}$ & $33 \mathrm{a}$ & 12.7 & 8.2 & 25 & 9 \\
\hline $\mathrm{I}-3$ & 20 & $100 \mathrm{a}$ & $32 \mathrm{a}$ & 8.1 & 4.8 & 26 & 46 \\
\hline $\mathrm{I}-4$ & 30 & $100 \mathrm{a}$ & $32 \mathrm{a}$ & 13.2 & 8.6 & 28 & 4 \\
\hline No fungicide & $\ldots$ & $100 \mathrm{a}$ & $44 \mathrm{a}$ & 14.2 & 8.9 & 0 & 0 \\
\hline$P($ ANOVA $)$ & $\ldots$ & $0.003 * *$ & $0.004 * *$ & $0.121 \mathrm{~ns}$ & $0.085 \mathrm{~ns}$ & $\ldots$ & $\ldots$ \\
\hline \multicolumn{8}{|l|}{2006} \\
\hline $\mathrm{I}-1$ & 0 & $79 b$ & $9 \mathrm{~b}$ & 6.7 & $2.7 \mathrm{a}$ & 36 & -15 \\
\hline $\mathrm{I}-2$ & 10 & $90 \mathrm{a}$ & $12 \mathrm{ab}$ & 6.1 & $2.0 \mathrm{bc}$ & 17 & 17 \\
\hline $\mathrm{I}-3$ & 20 & $94 \mathrm{a}$ & $14 \mathrm{a}$ & 4.7 & $1.6 \mathrm{c}$ & 0 & 34 \\
\hline $\mathrm{I}-4$ & 30 & $93 a$ & $14 \mathrm{a}$ & 5.1 & $2.0 \mathrm{bc}$ & 3 & 16 \\
\hline No fungicide & $\ldots$ & $91 \mathrm{a}$ & $14 \mathrm{a}$ & 5.1 & $2.4 \mathrm{ab}$ & 0 & 0 \\
\hline$P($ ANOVA $)$ & $\ldots$ & $0.025^{*}$ & $0.018 *$ & $0.672 \mathrm{~ns}$ & $0.007 * *$ & $\ldots$ & $\ldots$ \\
\hline
\end{tabular}

y Values for each treatment indicate the mean of three or four replications per treatment; ** and * indicate $P<0.01$ and 0.05 , respectively, for differences of each parameter (i.e., FHB I, FHB S, FDK, and DON+NIV) among treatments according to analysis of variance (ANOVA). Values within a year and column followed by the same letter are not significantly different according to Fisher's protected least significant difference test at $P=0.05$; ns $=$ nonsignificant differences among treatments.

${ }^{\mathrm{z}}$ Application timing of thiophanate-methyl fungicide application for each treatment is shown as the number of the days after anthesis (DAA). 
FDK level with treatment II-2 was significantly lower than that with treatment I-1. In 2006, although the effect of the treatments for FDK was not significant, the FDK level with treatment II-2 was also lowest among the treatments.

The control efficacy of each treatment (treatments I-1 and II-1 to -3) for FHB severity and mycotoxin content is also shown in Table 3 . The control efficacy value for FHB severity did not differ appreciably among the treatments in each year (i.e., 77 to 88 in 2005 and 36 to 49 in 2006). On the other hand, the control efficacy for mycotoxin content was quite different among the treatments; that is, 50 (treatment I-1) to 85 (treatment II-2) in 2005 and -15 (treatment I-1) to 52 (treatment II-2) in 2006.

In both of the comparisons among treatments (Tables 2 and 3), the control effect for FDK appeared to correspond to that for mycotoxin content rather than that for FHB severity. Although the effect of the treatments for FDK was not statistically significant, with the exception of the comparison between treatments I-1 and II- 1 to -3 in 2005, the 20-DAA application seemed to be associated with a lower FDK (\%) in each comparison (Tables 2 and 3 ).

\section{Discussion}

The results of our analyses indicated that the timing of fungicide application differentially affects FHB (disease) and mycotoxin concentration. Fungicide application at 20 DAA reduced the mycotoxin concentration in matured grain without reducing FHB, whereas application at anthesis was crucial for reducing FHB. Because FHB was assessed at 20 DAA, which is a generally adopted timing for FHB assessment (8), it is not surprising that no effect on FHB was observed in the 20-DAA application. The control efficacy of the 20-DAA application on mycotoxin concentration was 46 in 2005 and 34 in 2006 (Table 2). In the case of an additional application at 20 DAA after the 0-DAA application, the control efficacy was improved from 50 (treatment I-1) to 85 (treatment II-2) in 2005 and from -15 (treatment I-1) to 52 (treatment II2) in 2006 (Table 3).

To our knowledge, this is the first study to evaluate the effects of the timing of fungicide application at stages later than 20 DAA on FHB and mycotoxin accumulation in wheat. A 20-DAA fungicide application appeared to be effective in reducing mycotoxin. Although this result may be surprising, it is indeed reasonable, given the results of our previous study (47), which indicated that the late period of grain development is important in determining the final toxin contamination level in wheat. In that study, we found that (i) the amount of DON and NIV largely increased in wheat grain after 20 DAA (late milk stage), even with infection at earlier stages, and (ii) infection during later stages, at least as late as 20 DAA, can cause non-ignorable levels of contamination with these toxins in grain, even without clear FHB symptoms (47). Taking these previous findings into account, the 20-DAA fungicide application in this study appeared to reduce the amount of mycotoxin production by the fungi already infected during earlier stages and prevented primary infection after 20 DAA. The former effect is probably important, given that the effect of late stages of infection on the final mycotoxin level is generally low compared with that at early stages (earlier than 20 DAA) of infection $(6,7,47)$ and that the toxin-control efficacy of the 20-DAA application was higher than that of the 10-DAA application in all the experiments in this study.

It remains unclear, however, whether the 20-DAA fungicide application reduced the rate of mycotoxin production by interfering with trichothecene synthesis or prevented fungal development accompanying mycotoxin production. Investigations of the increase in mycotoxins and fungal biomass following $F$. graminearum species complex infection would provide further information on the effects of 20-DAA fungicide application as well as the manner in which mycotoxin is produced by the fungus during grain development.

The type of fungicide may affect the results of application. In this study, we used a wettable powder of thiophanate-methyl (Top$\sin \mathrm{M})$ as an aqueous solution, which is a broad-spectrum systemic fungicide with both preventive and curative properties. Thiophanate-methyl is converted to methyl benzimidazole carbamate (carbendazim), and this compound interferes with nuclear division in sensitive fungi. It is likely that the systemic or curative properties of thiophanate-methyl are critical to effectively control mycotoxin accumulation in grain, especially when applied at late stages. Nevertheless, the consistent results of 2 years of experiments using thiophanate-methyl and the findings from the previous study on the manner of mycotoxin accumulation during wheat grain development (47) suggest that around 20 DAA (late milk stage) is a potentially critical timing for mycotoxin control in wheat.

Although not statistically significant in most cases, at least numerically, fungicide application at 20 DAA appeared to be associated with lower FDK (percentage; Tables 2 and 3). It is likely that fungicide application at 20 DAA can be effective in reducing FDK (percentage) as well as mycotoxin concentration. To confirm this, however, further experiments are needed.

To date, several published reports have examined the control effect of fungicide application later than anthesis. However, the tested timings were limited (i.e., no later than 14 DAA), and the testing conditions in the previous studies did not appear appropriate or sufficient for the purpose of this study. Jones (13) tested the effect of additional fungicide application at 14 DAA following application at anthesis using other types of fungicides, such as benomyl, iprodione, mancozeb, and tebuconazole. The experiment

Table 3. Effect of the additional fungicide application at various timings after application at anthesis on Fusarium head blight (FHB) incidence (I), FHB severity (S), percentage of Fusarium-damaged kernels (FDK), and deoxynivalenol (DON) and nivalenol (NIV) concentration in wheat ('Norin 61') in each study year ${ }^{\mathrm{y}}$

\begin{tabular}{|c|c|c|c|c|c|c|c|}
\hline \multirow[b]{2}{*}{ Year, treatment } & \multirow[b]{2}{*}{$\mathbf{D A A}^{\mathbf{z}}$} & \multirow[b]{2}{*}{ FHB I (\%) } & \multirow[b]{2}{*}{ FHB S (0-100) } & \multirow[b]{2}{*}{$\operatorname{FDK}(\%)$} & \multirow[b]{2}{*}{ DON+NIV $(\boldsymbol{\mu g} / \mathrm{g})$} & \multicolumn{2}{|c|}{ Control efficacy for } \\
\hline & & & & & & FHB S & DON+NIV \\
\hline \multicolumn{8}{|l|}{2005} \\
\hline I-1 & 0 & 61 & 8 & $7.2 \mathrm{a}$ & 4.5 & 82 & 50 \\
\hline II-1 & $0+10$ & 51 & 5 & $3.7 \mathrm{ab}$ & 2.5 & 88 & 72 \\
\hline II-2 & $0+20$ & 59 & 7 & $2.4 \mathrm{~b}$ & 1.4 & 83 & 85 \\
\hline II-3 & $0+30$ & 73 & 10 & $6.4 \mathrm{a}$ & 3.9 & 77 & 57 \\
\hline$P($ ANOVA $)$ & $\ldots$ & $0.562 \mathrm{~ns}$ & $0.409 \mathrm{~ns}$ & $0.040^{*}$ & $0.073 \mathrm{~ns}$ & $\ldots$ & $\ldots$ \\
\hline \multicolumn{8}{|l|}{2006} \\
\hline I-1 & 0 & 79 & 9 & 6.7 & $2.7 \mathrm{a}$ & 36 & -15 \\
\hline II-1 & $0+10$ & 71 & 7 & 5.8 & $2.0 \mathrm{ab}$ & 49 & 17 \\
\hline II-2 & $0+20$ & 75 & 9 & 3.3 & $1.1 \mathrm{~b}$ & 38 & 52 \\
\hline II-3 & $0+30$ & 77 & 8 & 5.6 & $1.8 \mathrm{ab}$ & 41 & 25 \\
\hline$P$ (ANOVA) & $\ldots$ & $0.660 \mathrm{~ns}$ & $0.773 \mathrm{~ns}$ & $0.168 \mathrm{~ns}$ & $0.028^{*}$ & $\ldots$ & $\ldots$ \\
\hline
\end{tabular}

y Values for each treatment indicate the mean of three or four replications per treatment; $*$ indicates $P<0.05$ for differences in each parameter (i.e., FHB I, FHB S, FDK, and DON+NIV) among treatments according to analysis of variance (ANOVA). Values within a year and column followed by the same letter are not significantly different according to Fisher's protected least significant difference test at $P=0.05$; ns $=$ nonsignificant differences among treatments.

${ }^{\mathrm{z}}$ Application timing of thiophanate-methyl fungicide application for each treatment is shown as the number of the days after anthesis (DAA). 
was performed in a field without sprinkler irrigation for 1 year, and two applications did not perform better than a single application. Other studies $(30,34)$ examined the effect of different timings of fungicide applications with the following timings: $-5,-2,2$, and 5 DAA in the former and $-7,-2,2,5,7$, and 10 DAA in the latter. In both studies, the application closest to anthesis appeared to be most effective at reducing DON. However, in these studies, inoculation with fungal suspension was performed at anthesis. Therefore, these experiments assessed the effect of the timing of fungicide application relative to the timing of inoculation rather than the effect of the application timing per se (i.e., effect of host stage). In natural environments, infection pressure is not limited to anthesis.

Here, to assess the effects of the timing of fungicide application, we adopted an inoculation method using colonized maize kernels and sprinkler irrigation. It would be difficult to assess the effects of fungicide application timing by experiments with inoculation at specific timings or under natural infection conditions because, with such methods, the timing of inoculation or natural precipitation would affect the results. The inoculation method used in this study, which provided periodic moist conditions and generated $F$. graminearum species complex spores throughout the testing season, would be most appropriate for the purposes of this study. Using the same method, we previously evaluated the effects of fungicide-application timing on FHB and on mycotoxin accumulation in cleistogamous (closed-flowering) barley and revealed that the optimal timing for chemical control for cleistogamous barley is around the beginning of spent anther extrusion rather than at anthesis (48).

Given that wheat is most susceptible to FHB during anthesis $(3,26,32,39)$, fungicide application to control FHB and mycotoxin contamination is generally performed around anthesis $(4,12,13,19,20)$. Although fungicide application is one of the most practical methods of controlling FHB, the effect is not sufficiently high or consistent $(12,13,19,27,28)$. Fungicide efficacy varies between years and among test locations even when standard protocols are followed $(27,36)$. Additionally, the control efficacy of fungicide application on DON is generally not higher than that on FHB $(21,27,28)$. In this study, fungicide application at anthesis had a crucial effect on reducing FHB in both years, although the efficacy varied between years. On the other hand, in terms of reducing mycotoxin, it was effective in 2005 (control efficacy $=50$ ) but had no effect in 2006. This could be because the fungicide application at anthesis saved a particular portion of the grains that had been infected during early stages from heavily shriveling and, consequently, from being lost before maturity or at threshing, and the amount of such grains was large in 2006. This speculation is based on observations made during our previous study (47), in which accumulation of DON + NIV in grain by the 0-DAA inoculation was lower than that by the 10-DAA inoculation in some cases, whereas FHB severity was higher by the 0-DAA than the 10-DAA inoculation in most cases. These observations could be explained by the data for the number of mature grains per spike in that study, which suggested that a portion of the grains that were heavily damaged by the 0-DAA inoculation were shriveled and lost before maturity, leading to reduced toxin levels in the sample. It is also possible that the relative toxin-increase rate in the late stage was especially high in 2006, and the effect of fungicide application at anthesis was overwhelmed by maturity in that year, although the spore monitoring and the meteorological data do not appear to provide convincing evidence of this hypothesis.

Even if the toxin-reducing effect of fungicide application at anthesis is not sufficiently stable or high, fungicide application at this timing is crucial to reduce FHB (disease). In Japan, generally, fungicide application around anthesis against FHB is necessary in wheat production. Additional applications are recommended when one application is not expected to be sufficient to control FHB and mycotoxin contamination depending on the individual production situations, including weather and the resistance level of the cultivars. The first additional application is generally suggested at 7 to 10 days after the initial application (i.e., usually 7 to 10 DAA). However, our results suggest that approximately 20 DAA is the best timing for an additional application to control mycotoxin concentration, at least when a wettable powder of thiophanate-methyl is used, although the difference in the toxin-reducing effect between the 10- and 20-DAA applications was not statistically significant in all cases (Tables 2 and 3). The effect of a 20-DAA fungicide application may be fungicide specific, as noted above, and the effective fungicides for early- and late-stage applications may differ. Further studies are needed to evaluate the effect of latestage fungicide applications using additional wheat cultivars and fungicides with properties or modes of action different from those of thiophanate-methyl.

\section{Acknowledgments}

This study was funded by the Ministry of Agriculture, Forestry, and Fisheries of Japan, as part of the Research Project for Ensuring Food Safety from Farm to Table and Integrated Research Program for Functionality and Safety of Food toward an Establishment of Healthy Diets.

\section{Literature Cited}

1. Anonymous. 2010. Annual Inventory of Registered Pesticides and Their Use. Japan Plant Protection Association, Tokyo. (In Japanese)

2. Anonymous. 2010. Annual Statistics on Pests and Pesticides. Japan Plant Protection Association, Tokyo. (In Japanese)

3. Atanasoff, D. 1920. Fusarium-blight (scab) of wheat and other cereals. J. Agric. Res. 20:1-40.

4. Blandino, M., Minelli, L., and Reyneri, A. 2006. Strategies for the chemical control of Fusarium head blight: effect on yield, alveographic parameters and deoxynivalenol contamination in winter wheat grain. Eur. J. Agron. 25:193-201.

5. Campbell, K. A. G., and Lipps, P. E. 1998. Allocation of resources: sources of variation in Fusarium head blight screening nurseries. Phytopathology 88:1078-1086.

6. Cowger, C., and Arrellano, C. 2010. Plump kernels with high deoxynivalenol linked to late Gibberella zeae infection and marginal disease conditions in winter wheat. Phytopathology 100:719-728.

7. Del Ponte, E. M., Fernandes, J. M. C., and Bergstrom, G. C. 2007. Influence of growth stage on Fusarium head blight and deoxynivalenol production in wheat. J. Phytopathol. 155:577-581.

8. Dill-Macky, R. 2003. Inoculation methods and evaluation of Fusarium head blight resistance in wheat. Pages 184-210 in: Fusarium Head Blight of Wheat and Barley. K. J. Leonard and W. R. Bushnell, eds. American Phytopathological Society, St. Paul, MN.

9. Haidukowski1, M., Pascale1, M., Perrone1, G., Pancaldi, D., Campagna, C. and Visconti, A. 2005. Effect of fungicides on the development of Fusarium head blight, yield and deoxynivalenol accumulation in wheat inoculated under field conditions with Fusarium graminearum and Fusarium culmorum. J. Sci. Food Agric. 85:191-198.

10. Ichinoe, M., Hagiwara, H., and Kurata, H. 1984. Distribution of trichothecene-producing fungi in barley and wheat fields in Japan. Pages 190-198 in: Toxigenic Fungi: Their Toxins and Health Hazard. H. Kurata and Y. Ueno, eds. Elsevier, Tokyo.

11. Ichinoe, M., Kurata, H., Sugiura, Y., and Ueno, Y. 1983. Chemotaxonomy of Gibberella zeae with special reference to production of trichothecenes and zearalenone. Appl. Environ. Microbiol. 46:1364-1369.

12. Ioos, R., Belhadj, A., Menez, M., and Faure, A. 2005. The effects of fungicides on Fusarium spp. and Microdochium nivale and their associated trichothecene mycotoxins in French naturally-infected cereal grains. Crop Prot. 24:894-902.

13. Jones, R. K. 2000. Assessments of Fusarium head blight of wheat and barley in response to fungicide treatment. Plant Dis. 84:1021-1030.

14. Koizumi, S., Kato, H., Yoshino, R., Komada, H., Ichinoe, M., Umehara, Y., and Hayashi, N. 1997. Pathogenicity and ecology of Fusarium species associated with wheat and barley scab in Japan. Bull. Inst. Compr. Agric. Sci. Kinki Univ. 5:31-45.

15. Lee, T., Han, Y. K., Kim, K. H., Yun, S. H., and Lee, Y. W. 2002. Tri 13 and Tri 7 determine deoxynivalenol- and nivalenol-producing chemotypes of Gibberella zeae. Appl. Environ. Microbiol. 68:2148-2154.

16. Lehoczki-Krsjak, S., Szabó-Hevér, Á., Tóth, B., Kótai, C., Bartók, T., Varga, M., Farády, L., and Mesterházy, Á. 2010. Prevention of Fusarium mycotoxin contamination by breeding and fungicide application to wheat. Food Addit. Contam. 27:616-628.

17. Liddell, C. M. 2003. Systematics of Fusarium species and allies associated with Fusarium head blight. Pages 35-43 in: Fusarium Head Blight of Wheat and Barley. K. J. Leonard and W. R. Bushnell, eds. American Phytopathological Society, St. Paul, MN.

18. McMullen, M., Jones, R., and Gallenberg, D. 1997. Scab of wheat and barley: a re-emerging disease of devastating impact. Plant Dis. 81:13401348 .

19. Mesterházy, Á. 2003. Control of Fusarium head blight of wheat by fungicides. Pages 363-380 in: Fusarium Head Blight of Wheat and Barley. K. J. Leonard and W. R. Bushnell, eds. American Phyto- 
pathological Society, St. Paul, MN

20. Mesterházy, Á., Bartók, T., and Lamper, C. 2003. Influence of wheat cultivar, species of Fusarium, and isolate aggressiveness on the efficacy of fungicides for control of Fusarium head blight. Plant Dis. 87:1107-1115.

21. Nakajima, T. 2007. Progress and outlook for the control of nivalenol and deoxynivalenol contamination due to Fusarium head blight in wheat. Mycotoxins 57:129-134.

22. Nakajima, T., and Yoshida, M. 2007. Mycotoxin productivity and virulence of Fusarium graminearum species complex causing Fusarium head blight on wheat and barley in the western part of Japan. Jpn. J. Phytopathol. 73:106-111. (In Japanese with English abstract.)

23. O’Donnell, K., Kistler, H. C., Tacke, B. K., and Casper, H. H. 2000. Gene genealogies reveal global phylogeographic structure and reproductive isolation among lineages of Fusarium graminearum, the fungus causing wheat scab. Proc. Natl. Acad. Sci. USA 97:7905-7910.

24. O’Donnell, K., Ward, T. J., Aberra, D., Kistler, H. C., Aoki, T., Orwig, N., Kimura, M., Bjørnstad, Å., and Klemsdal, S. S. 2008. Multilocus genotyping and molecular phylogenetics resolve a novel head blight pathogen within the Fusarium graminearum species complex from Ethiopia. Fungal Genet. Biol. 45:1514-1522.

25. O'Donnell, K., Ward, T. J., Geiser, D. M., Kistler, H. C., and Aoki, T. 2004. Genealogical concordance between the mating type locus and seven other nuclear genes supports formal recognition of nine phylogenetically distinct species within the Fusarium graminearum clade. Fungal Genet. Biol. 41:600-623.

26. Parry, D. W., Jenkinson, P., and McLeod, L. 1995. Fusarium ear blight (scab) in small-grain cereals: a review. Plant Pathol. 44:207-238.

27. Paul, P. A., Lipps, P. E., Hershman, D. E., McMullen, M. P., Draper, M. A., and Madden, L. V. 2007. A quantitative review of tebuconazole effect on Fusarium head blight and deoxynivalenol content in wheat. Phytopathology 97:211-220.

28. Paul, P. A., Lipps, P. E., Hershman, D. E., McMullen, M. P., Draper, M. A., and Madden, L. V. 2008. Efficacy of triazole-based fungicides for Fusarium head blight and deoxynivalenol control in wheat: a multivariate meta-analysis. Phytopathology 98:999-1011.

29. Pirgozilev, S. R., Edwards, S. G., Hare, M. C., and Jenkinson, P. 2003. Strategies for the control of Fusarium head blight in cereals. Eur. J. Plant Pathol. 109:731-742.

30. Pirgozliev, S. R., Ray, R. V., Edwards, S. G., Hare, M. C., and Jenkinson, P. 2008. Effect of timing of fungicide application on the development of Fusarium head blight and the accumulation of deoxynivalenol (DON) in winter wheat grain. Cereal Res. Commun. 36:289-299.

31. Placinta, C. M., D’Mello, J. B. F., and Macdonald, A. M. C. 1999. A review of world contamination of cereal grains and animal feeds with Fusarium mycotoxins. Anim. Feed Sci. Technol. 78:21-37.

32. Pugh, G. W., Johann, H., and Dickson, J. G. 1933. Factors affecting infection of wheat heads by Gibberella saubinetii. J. Agric. Res. 46:771-797.

33. Ryu, J., Ohtsubo, K., Izumiyama, N., Nakamura, K., Tanaka, T., Yamamura, H., and Ueno, Y. 1988. The acute and chronic toxicities of nivalenol in mice. Fundam. Appl. Toxicol. 11:38-47.

34. Scheider, N., Guo, J. R., Verreet, J. A., and Beyer, M. 2009. Assessing the intensity of Fusarium damage in wheat: a comparison of selected disease parameters during disease development and the role of fungicides. J. Plant Dis. Prot.116:118-123

35. Seo, J. A., Kim, J. C., Lee, D. H., and Lee, Y. W. 1996. Variation in 8-ketotrichothecenes and zearalenone production by Fusarium graminearum isolates from corn and barley in Korea. Mycopathologia 134:31-37.

36. Šíp, V., Chrpová, J., Veškrna, O., and Bobková, L. 2010. The impact of cultivar resistance and fungicide treatment on mycotoxin content in grain and yield losses caused by Fusarium head blight in wheat. Czech J. Genet. Plant Breed. 46:21-26.

37. Starkey, D. E., Ward, T. J., Aoki, T., Gale, L. R., Kistler, H. C., Geiser, D. M., Suga, H., Toth, B., Varga, J., and O’Donnell, K. 2007. Global molecular surveillance reveals novel Fusarium head blight species and trichothecene toxin diversity. Fungal Genet. Biol. 44:1191-1204.

38. Suga, H., Karugia, G. W., Ward, T., Gale, L. R, Tomimura, K., Nakajima, T., Miyasaka, A., Koizumi, S., Kageyama, K., and Hyakumachi, M. 2008. Molecular characterization of the Fusarium graminearum species complex in Japan. Phytopathology 98:159-166.

39. Sutton, J. C. 1982. Epidemiology of wheat head blight and maize ear rot caused by Fusarium graminearum. Can. J. Plant Pathol. 4:195-209.

40. Takahashi, M., Shibutani, M., Sugita-Konishi, Y., Aihara, M., Inoue, K., Woo, G., Fujimoto, H., and Hirose, M. 2008. A 90-day subchronic toxicity study of nivalenol, a trichothecene mycotoxin, in F344 rats. Food Chem. Toxicol. 46:125-135.

41. Tanaka, T., Hasegawa, A., Yamamoto, S., Lee, U. S., Sugiura, Y., and Ueno, Y. 1988. Worldwide contamination of cereals by the Fusarium mycotoxins nivalenol, deoxynivalenol, and zearalenone. 1. Survey of 19 countries. J. Agric. Food Chem. 36:979-983.

42. Tanaka, T., and Sugiura, Y. 2003. Levels and pattern of contamination with trichothecenes in cereal grains and their risk assessment. Mycotoxins 53:119-121.

43. Togawa, M. 1994. Selective medium for isolation of Fusarium graminearum. Soil Microorg. 44:77-88. (In Japanese with English abstract)

44. Ueno, Y., Aikawa, Y., Okumura, H., Sugiura, Y., Nakamura, K., Masuma, R., Tanaka, T., Young, C. J., and Savard, M. E. 1997. Trichothecenes produced by Fusarium species Fn 2B. Mycotoxins 45:25-31.

45. Ward, T. J., Bielawski, J. P., Kistler, H. C., Sullivan, E., and O'Donnell, K. 2002. Ancestral polymorphism and adaptive evolution in the trichothecene mycotoxin gene cluster of phytopathogenic Fusarium. Proc. Natl. Acad. Sci. USA 99:9278-9283.

46. Yli-Mattila, T., Gagkaeva, T., Ward, T. J., Aoki, T., Kistler, H. C., and O'Donnell, K. 2009. A novel Asian clade within the Fusarium graminearum species complex includes a newly discovered cereal head blight pathogen from the Russian Far East. Mycologia 101:841-852.

47. Yoshida, M., and Nakajima, T. 2010. Deoxynivalenol and nivalenol accumulation in wheat infected with Fusarium graminearum during grain development. Phytopathology 100:763-773.

48. Yoshida, M., Nakajima, T., Arai, M., Suzuki, F., and Tomimura, K. 2008. Effect of the timing of fungicide application on Fusarium head blight and mycotoxin accumulation in closed-flowering barley. Plant Dis. 92:11641170

49. Yoshida, M., Nakajima, T., and Tonooka, T. 2008. Effect of nitrogen application at anthesis on Fusarium head blight and mycotoxin accumulation in breadmaking wheat in the western part of Japan. J. Gen. Plant Pathol. 74:355-363.

50. Yoshizawa, T. 1997. Geographic difference in trichothecene occurrence in Japanese wheat and barley. Bull. Inst. Compr. Agric. Sci. Kinki Univ. 5:2330.

51. Yoshizawa, T., and Jin, T. Z. 1998. Trichothecene occurrence in Japanese wheat and barley-its characteristics. Mycotoxins 47:15-18.

52. Yoshizawa, T., Kohno, H., Ikeda, K., Shinoda, T., Yokohama, H., Morita, K., Kusada, O., and Kobayashi, Y. 2004. A practical method for measuring deoxynivalenol, nivalenol, and T-2 + HT-2 toxin in foods by an enzymelinked immunosorbent assay using monoclonal antibodies. Biosci. Biotechnol. Biochem. 68:2076-2085

53. Zadoks, J. C., Chang, T. T., and Konzak, C. F. 1974. A decimal code for the growth stages of cereals. Weed Res. 14:415-421. 